\title{
Rebooting Engaged Pedagogy: Strategies for Making Online Classrooms Dynamic, Inclusive and Holistic During The COVID-19 Era and Beyond
}

\author{
Dr. Juli Hinds \\ Medaille College, United States
}

"All of us in the academy and in culture as a whole are called to renew our minds if we are to transform educational institutions — and society — 'so that how' we live, teach, and work can reflect our joy in cultural diversity, our passion for justice, and our love of freedom.”

bell hooks, "Teaching to Transgress"

\begin{abstract}
:
The global health crisis of COVID 19 came at a time when most American universities and colleges were well into their 2020 spring semesters and quarters. As the United States struggled to control the spread of coronavirus through social distancing, higher education adapted by switching to various forms of online learning. As infection rates grew, the public health and economic crisis became clear. Within this period, data emerged suggesting that racial and ethnic minorities -- the most marginalized individuals in the U.S. -- were most at risk in terms of significant health effects and financial devastation from the economic shut-down. Additionally, many marginalized students returned to homes without wifi, as well as other tools, such as computers, which are necessary for success with online schooling. ${ }^{1}$ By the academic year's end across the nation, powerful protests arose demanding racial justice and police reform after the murder of George Floyd by Minneapolis police. But the unrest did not stop with the police. As summer descended, political talk shows and newspaper editorial pages filled with conversations about systemic racism and reckoning in American institutions, including our colleges and universities.
\end{abstract}

\footnotetext{
${ }^{1}$ Within this re-evaluation is a recognition that even prior to COVID-19, higher education reflected the abysmal inequalities that existed within American culture--inequalities such as school funding, achievement gaps, graduation rates and other barriers.
} 


\section{2nd World Conference on Teaching and Education}

Abruptly, within this social, economic and public health upheaval, educators, many who had not taught remotely, grappled with transitioning to online learning, while, at the same time, fearing that their on-the-ground approach to teaching might be lost. How might instructors craft a remote learning space that could replicate, and perhaps even deepen, the connectivity and vigor of the inperson experience? As an instructor in a communications department, at a small liberal arts college, I sought answers to these questions by looking at online best practices, such as concepts of social presence, and connectivity. ${ }^{2}$ I asked myself, how might instructors reimagine our online classroom within the broader cultural reckoning on issues of race, class, gender and power? In pursuit of answers, I turned to an educational scholar whose work continuously inspires me: educator and thinker bell hooks. hooks' Engaged Pedagogy, an educational approach that combines critical race, feminist and multicultural theory, argues for a learning space that at its core is 'engaging' for the students and the teachers, while also serving as 'a site of resistance' against hierarchical rote learning. Social presence and connectivity, core themes in online learning were driven, as by online scholars, much like hooks, that were inspired to create classrooms that feel authentic, engaging and dynamic. Yet, there is a difference. Critical engaged pedagogy is nourished by an agenda, to disrupt teaching hierarchies, actually confront the inequities, and political claims within society. An engaged classroom is not just a place to create community but a space for liberation. For educators who recognize the need to engage with their students, and the social cultural issues surrounding and underpinning our current moment, moving engaged pedagogy online is a place to start. Therefore, while hooks' engaged pedagogy is a powerful framework for higher education practitioners in normal times, I argue that her work is especially pertinent to pandemic-imposed online teaching ${ }^{3} \quad$ hooks inspired me to create online classes that were socially connective, and dynamic. Through close engagement with her ideas, I developed a series of online activities based on three of hooks' engaged pedagogical paradigms: 1.) learning as transformative, 2.) learning as rooted in passion and joy, and 3.) learning as situated in a holistic classroom built upon reciprocity. In this article, I explore these three principles within hooks' scholarship. Then, I provide five activities for online teaching that align with the rigor and liberatory purposes of engaged pedagogy. These strategies are intended to help educators rethink, reframe and revitalize their online classrooms now and after the COVID-19 pandemic.

Keywords: Engaged Pedagogy, Online learning, Holistic Learning, Critical Race Theory, Gender Theory

\footnotetext{
${ }^{2}$ Oh, CS, Bailenson JN \& Welch GF (2018) A Systematic Review of Social Presence: Definition, Antecedents, and Implications.

${ }^{3}$ Hooks B (1994) Teaching to Transgress: Education as the practice of freedom Routledge, New York 


\section{2nd World Conference on Teaching and Education}

19-21 February, 2021

Vienna, AUSTRIA

\section{Learning as Transformative}

"We learned early that our devotion to learning, to a life of the mind, was a counterhegemonic act, a fundamental way to resist every strategy of white racist colonization.

"bell hooks (3)

In the engaged classroom, teachers and students are encouraged to bring their unique knowledge, voices and experiences to discussions and their scholarly work. This recognition of a student's particular wisdom runs counter to traditional educational approaches that focus on didactic, hierarchical learning. Professors invested in creating curriculum that confronts inherent biases and systems of oppression must surrender to the idea that they are all knowing authority on every topic. In this way, a teacher, hooks suggest, can see the classroom as "a site of resistance" (2). To teach this way, an instructor must look for opportunities for being vulnerable and sharing first bits of their own stories and struggles so students feel safe to come forward with their own perspective. learning can become transformative as we learn from each other, enriching our understanding of issues such as the intersectionality of class, gender, race, disabilities, and gender orientation. This vulnerability has its limitations, however; such as, Scholar Regina Berry notes that sharing stories "does not alleviate the historical power of the teacher/professor and thereby can limit the freedom of speech in the classroom setting." $(26)^{4}$ hooks in response implies that a vigilant awareness of this power shift is met through acknowledgement to her students that "if my knowledge is limited" and a student brings "a combination of facts and experience, then I humble myself and respectfully learn from those who bring this great gift." (89) In the applied online strategies section So What's Your Story and Open Heart Sessions exercises build upon this process of learning driven by passion and joy.

\section{Learning Driven by Passion and Joy}

The first paradigm that shaped my pedagogy was the classroom should be an exciting place. bell hooks (7) hooks' advocacy for joy in learning, "sometimes even fun" for the teacher and the student was unparalleled within "serious" scholarly discourse, where "excitement in higher education" is framed "as potentially disruptive of the atmosphere of seriousness assumed to be essential to the learning process." (7) Yet, to foster transformative learning, a space where students feel safe and encouraged to speak, a teacher must first model this 'unorthodox' position of human passion and joy. A focus on bringing joy to the classroom was hooks' first paradigm within engaged pedagogy, and can be traced to her educational narrative. In her youth she saw excitement as a child learner in a predominately black public school system with black educators in the South. Here hooks' teachers were passionate about learning and echoed the proverbial view of knowledge as power. Her teachers were "on a mission." (2) This insistence on joy spoke to me as an instructor struggling to find the energy to teach four different classes online in the Spring

\footnotetext{
${ }^{4}$ Berry, T. (2010) "Engaged pedagogy and critical race feminism" Educational Foundations
} 


\title{
2nd World Conference on Teaching and Education
}

of 2020. hooks give permission to often overworked teachers with less resources to seek ways to bring joy to the classroom. In this perspective, educators are encouraged to focus on themselves so they can then be there for their students. In the online learning strategies section, this passion and joy in the classroom is echoed in the prompts of the Teacher Welcome Video and Thank you for Showing up for Yourself. These examples are intended to provoke joy, which ultimately fuels learning as transformative, and in turn feeds the growth and nourishment of the holistic classroom.

\section{The holistic classroom built upon reciprocity.}

\begin{abstract}
Engaged pedagogy does not seek simply to empower students. Any classroom that employs a holistic model of learning will also be a place where teachers grow, and are empowered by the process. bell hooks (21)
\end{abstract}

Reciprocity in the learning environment is strengthened with a focus on self-actualization not just for the students but the teacher as well. (21) hooks again leaned into her educational history, this time through her experiences in graduate school, where she witnessed instructors who frequently taught in an unconscious rigid fashion. She writes, "they were not self-actualized, they often used the classroom to enact rituals of control that were about domination and unjust exercise of power." (4) In contrast, engaged instructors strive for authenticity and self-actualization, which necessitates the practice of vulnerability. This joyful co-creation of the classroom experience, rooted in shared vulnerability, ultimately leads to the holistic classroom. In the holistic classroom reciprocity is always in-process.

Education scholar Lamar L. Johnson provides examples of this productive vulnerability when he discusses bringing his racial identity to the class in an effort to increase students' understanding of course content focused on racial justice work, ${ }^{5}$ (5) Additionally, Johnson writes about how vulnerability can be liberatory because the teacher removes the mask of authority and actually presents themselves as a human being with a particular history. In the online learning strategies section, one exercise that encourages this sharing of human experiences is "So What's Your Story." This exercise encourages students to share and listen to one another's stories. This sharing is an essential component of building the holistic classroom because it encourages disclosure, often empowering the students because they gain a sense that their stories matter, and their experiences are valuable to the classroom holistic environment.

\section{Your online classroom through five engaged pedagogical strategies.}

\footnotetext{
5 Johnson, L. (2017) The Racial Hauntings of One Black Male Professor and the Disturbance of the Self(ves): SelfActualization and Racial Storytelling as Pedagogical Practices
} 


\section{2nd World Conference on Teaching and Education}

19-21 February, 2021

Vienna, AUSTRIA

Below, I offer five strategies informed by Engaged Pedagogy that help create online learning environments that are transformative, reclaim teacher and student joy and passion into the learning space, and ultimately foster an inclusive, holistic, and dynamic classroom.

\section{1) Learning as transformative}

\section{So what's your story?}

In an engaged pedagogical classroom, reciprocity of shared experiences fosters a holistic and inclusive learning space that is often transformative. So, what's your story follows hooks' invitation for teachers to encourage student self-expression, while also modeling respect for their classmates' stories. So, what's your story also lines up with best online practices of social presence and connectivity. In this activity, which takes place in a synchronous online session, students interview each other in randomly paired-up dyads while the rest of the class listens. Within the dyad, a student queries the other, then they reverse roles. All of the students are provided a list of open-ended questions meant to solicit the descriptive responses. Students are encouraged to approach this assignment not as 'interviews' but as conversations. Question include: What has been your biggest challenge? What would no one suspect about you? What makes you emotional or excited? Prior to the start, the teacher reminds students that if they are uncomfortable with a question, they can choose another. Classmates not in the discussion are encouraged to close their eyes and listen for what connects with them. The authenticity of student answers and stories are frequently candid and soulful. Following the So, what's your story conversation, the remaining students are encouraged to write positive thoughts or support through the chat-board. This exercise has consistently cultivated community, and student evaluations consistently list it as their favorite.

\section{Open Heart Sessions}

hooks challenges teachers to generate flexible and democratic spaces not just to empower their students but themselves as educators and to offer their own voice and lived experiences. This idea led to Open Heart Sessions. In Open Heart Sessions the goal is give a student freedom to reveal an aspect of themselves through a mode of their choosing, i.e. a story, poetry, singing a song, a Tik Tok, or movie short. Besides enhancing self-reflection, I found this activity cultivated community, through the shared act of vulnerability. Open Heart Sessions is useful in the live classroom, or through a discussion board, where a student uploads the activity. In one of my classes in the spring students decided to share synchronously. The students took turns as moderators, presenting their work through their application screen. One student from Jamaica decided to share several of her favorite poems or quotes from authors of their native country. One quote from actor and activist Grace Jones, fueled rich discussion:

They used to call me Firefly when I was a little girl, and I always tried to figure out why I was being called a firefly. I was really black, black, black from the sun. After being in Jamaica for 13 years, my eyes were 


\section{2nd World Conference on Teaching and Education}

19-21 February, 2021

Vienna, AUSTRIA

really beady and white, and my skin was really black. I must have really looked like a fly. My eyes looked like lights, like stars.

Classmates are encouraged to comment following the share. In this instance, students wrote in the chat board. Some asked, who is Grace Jones? Do you miss Jamaica? This led to open discourse on the influences of place and identity. Open Heart Sessions make space for personal expression that nurtures differing ways of knowing. Just as the teacher must reflect and strive to bring their authentic self, the student is encouraged to bring their stories and particular views.

\section{Learning driven by passion and joy}

\section{Teachers' Welcome Video-Keep It Real!}

"Teaching is a performative act," writes bell hooks:ot in the conventional sense as "spectacle' but as a catalyst for engaging with an audience. (11) One way to engage with students is through a personalized welcoming video. Much like a syllabus offers students an early glimpse of the course, your teacher video is an asynchronous humanized first impression. This is the chance to have fun, to rethink how you bring yourself into the classroom, while also tapping into social presence for the students. As you set up your course for the semester, upload a video of yourself specifically addressing the class. Record it in an environment that feels real, i.e. your home with your cat, or in your office with your favorite movie poster behind you, whatever. The video can provide students with basic details: Where is the syllabus? What to expect on the first day? To what book to buy? Keep the video short, under three minutes or so; this way a student will be tempted to watch. Most importantly be authentic: bring your warmth and enthusiasm. The video does not need to be fancy, in fact shoot from your phone, if possible, it comes off as more human and natural, which counter traditional concepts of educators as rigid purveyors of knowledge. It also models excitement for learning, setting in motion the dynamic classroom. View my welcome video, recorded from my iphone, created for an American Pop Culture course: https:// youtu.be/RRnEdIAQqmo

\section{Thank You for Showing up for Yourselves}

Prior to Covid, with on-the-ground learning, at the end of class, I would applaud and say to students Thank you for Showing up for Yourselves! Students and I would frequently high-five as they left the room. It was a way to wrap up a lecture, show the students appreciation, have some fun, and remind learners that 'showing-up' is a gift you give yourself. This taps into hooks recognition, of the "joys of education as the practice of freedom, for it allows students to assume responsibility for their choices." In shifting this online for the synchronous class, the instructor encourages students to go back to the chat board before they log-out. The teacher can say or simply write out, thank you for Showing up for Yourselves. Students are encouraged to exit with their own 


\section{2nd World Conference on Teaching and Education}

19-21 February, 2021

Vienna, AUSTRIA

farewell response. As the semester progresses, this can become a community bonding experience as students frequently get more inventive with our farewells and thank-you prompts, using emojis, explanation marks or getting silly with remarks, such as my personal favorite response from a student, thank you for showing up for the planet!

\section{5) Check-in Meditation}

In an engaged pedagogical learning space there is "an ongoing recognition that everyone influences the classroom dynamic."This begins with the professor modeling self-care, so they can be socially present. The Check-in Meditation is a powerful strategy for a teacher to take a beat at the start of class, ultimately modeling self-care and humanity. This exercise was particularly useful in the Spring and Fall of 2020, when many students and faculty and myself were feeling frightened, lonely or overwhelmed. This exercise has three parts. First, while students are logging in, they are prompted to type in a one-word description, if they choose, of how they are currently feeling, emojis welcome. The instructor also types in their word. Then, as each student joins they contribute. Secondly, within the first few minutes of class, collectively the instructor and the students take time for a breathing meditation (then three-beat breaths in, hold for three beats and then breath out for three beats). The teacher reminds students that they do not have to participate in the meditation, yet are encouraged to be still. Then, the class repeats the 'check-in' prompt through chat-board. Often students will express calmer states, and or relief that they are not alone in their particular mood. This exercise has many dividends, It positions the educator as bringing their human self into the space, thus giving permission for others to do the same. It generates the tone at the beginning of class to engage within the learning space. Additionally, as the semester progresses, there is often an ongoing acknowledgment that on different days' individuals can share and exhibit an array of human feelings. This chance to see and remember our humanity and our need to care for self and others, is foundational to a truly rich engaged pedagogy.

\section{Conclusion}

This paper provides specific strategies for rebooting your online classes through the theoretical lens of engaged pedagogy. At its core, engaged pedagogy challenges rote and staid modes of teaching and top-down learning environment. It affords and makes room for educators to model their own humanity, while equally supporting the lived experiences of learners from varying social, cultural and economic positions. It is not surprising that engaged pedagogical paradigms are reflected in some of the best online practices, where the goals are to create remote learning that have high social presence and connectivity. Yet, in the economic, political and social upheaval of this moment, best practices are not enough. We as educators need to do more, not just for our students but for ourselves. This work argues that while engaged pedagogy is a forceful framework 


\section{2nd World Conference on Teaching and Education}

for educators in non-pandemic times, engaged pedagogy's key paradigms are exceedingly relevant in this moment. As teachers and students grapple to learn and co-create effective and inclusive online learning communities, engaged pedagogy can prove a powerful reference point for the creation of a classroom experience that is transformative, dynamic and holistic.

\section{Bibliography}

Berry, T. (2010) "Engaged Pedagogy and Critical Race Feminism" Educational Foundations, V24, P19-26.

Dunlap, J. C., \& Lowenthal, P. R. (2010a). What's your best learning experience? What students' stories tell us about engaging teaching and learning. Paper presented at the American Educational Research Association (AERA) annual conference, Denver, CO

Hooks B (1994) Teaching to Transgress: Education as the practice of freedom Routledge, New York

Johnson, L. (2017) The Racial Hauntings of One Black Male Professor and the Disturbance of the Self(ves): Self-Actualization and Racial Storytelling as Pedagogical Practices

Lowenthal, P. \& Dunlap, J. (2009). From pixel on a screen to real person in your students' lives: Establishing social presence using digital storytelling. The Internet and Higher Education. 13. 7072.

10.1016/j.iheduc.2009.10.004.

Yuan, J., \& Kim, C. (2014). Guidelines for facilitating the development of learning communities in online courses. Journal of Computer Assisted Learning, 30, 220-232. 